\title{
DISPOSITIVO DE PROTEÇÃO OCULAR PARA RECÉM-NASCIDOS EM TRATAMENTO DE FOTOTERAPIA: RELATO DE EXPERIÊNCIA ${ }^{1}$
}

\section{Morgana Aline da Silva²; Luiza Fortes Lamberty3; Ticiana Aita Xavier4; Regina Gema Santini Costenaro ${ }^{5}$}

\section{RESUMO}

Objetiva-se com este estudo, relatar a experiência de acadêmicos de enfermagem na criação e utilização de um dispositivo de proteção ocular utilizado em recém-nascidos que estavam em tratamento de fototerapia em uma maternidade.Trata-se de um relato de experiência, transcrito a partir das vivências das acadêmicas frente ao serviço prestado ao $\mathrm{RN}$ na maternidade, no período do primeiro semestre de 2021 como atividade extensionista da disciplina de Atenção Integral à Saúde do RN, da Criança e do Adolescente. Para descrição das atividades, evidenciou-se a necessidade da criação de um dispositivo de proteção ocular para o uso associado ao tratamento de fototerapia em recém-nascidos institucionalizados. Sendo assim conclui-se que, o protetor ocular ajuda e bloqueia a passagem dos raios de luz irradiados pelo equipamento de fototerapia, contribui na proteção e prevenção de agravos provenientes desse tratamento.

Palavras-chave: Enfermagem; Fototerapia; Recém-nascido.

Eixo Temático: Atenção Integral e Promoção à Saúde.

\section{INTRODUÇÃO}

A icterícia é o sinal clínico mais comum observado em recém-nascidos em berçários ou alojamento conjunto. O neonato tirado do ambiente intrauterino, tem a necessidade de ajustar-se à vida extrauterina e passa a depender de substratos para a manutenção de seu ritmo de crescimento e a suportar as exigências energéticas de sua massa tecidual. Esta necessidade calórica depende da atividade hepática (SILVA et al., 2008).

\footnotetext{
${ }^{1}$ Relato desenvolvido como atividade para uma disciplina da graduação de enfermagem. ${ }^{2}$ Acadêmica do Curso de Enfermagem. Universidade Franciscana - UFN. E-mail: morgana.aline@ufn.edu.br.

${ }^{3}$ Acadêmica do Curso de Enfermagem. Universidade Franciscana - UFN. E-mail: luizaflamberty@gmail.com.

${ }^{4}$ Aluna do Mestrado profissional em saúde Materna e infantil. Universidade Franciscana- Santa maria-RS. ticiana.xavier@ufn.edu.br

${ }^{5}$ Professora Curso de enfermagem e Mestrado Profissional em Saúde Materna e InfantilUniversidade Franciscana- Santa Maria RS. regina@ufn.edu.br
} 
Nos primeiros dias de vida os recém-nascidos podem desenvolver hiper bilirrubinemia clinicamente detectável, ocorrendo em cerca de $60 \%$ dos RN. Sendo que na maioria das vezes que ocorre, retrata um acontecimento fisiológico transitório, não necessitando de intervenção terapêutica (BRASIL, 2011).

Quando necessário uma intervenção terapêutica, a mais utilizada mundialmente é a fototerapia. É um tratamento onde se coloca o recém-nascido em um berço usando apenas fralda e com os olhos protegidos, sobre a exposição de uma luz fluorescente branca ou azul, sendo conhecido também como "banho de luz" (BRASIL, 2011).

Nesse contexto, as alterações oculares decorrentes da fototerapia podem ser ocasionadas tanto por uma exposição acidental à energia luminosa, devido ao uso e/ou posicionamento inadequado do protetor ocular, quanto pela não dispensação dos cuidados oculares recomendados durante a terapêutica (GONÇALVES et al., 2016).

De acordo com o vivenciado em campo prático em uma unidade de internação obstétrica as acadêmicas de enfermagem, desenvolveram um produto tecnológico do tipo protetor ocular artesanal, simples e de fácil uso e higiene, oferecendo a mesma eficácia de um protetor adquirido externamente.

Objetiva-se com este estudo, relatar a experiência de acadêmicos de enfermagem na criação e utilização de um dispositivo de proteção ocular utilizado em recém-nascidos que estavam em tratamento de fototerapia em uma maternidade.

\section{METODOLOGIA}

Este respectivo estudo trata-se de um relato de experiência, elaborado a partir das vivências e conhecimentos práticos de acadêmicas em formação, ao exercer atividades no cenário prático no curso de Enfermagem. Foi criado um dispositivo de proteção ocular que possibilitasse aumento do bem estar do paciente sem desconciderar a alta necessidade de proteção para evitar possiveis complicações. $O$ desenvolvimento do dispositivo se deu através da visualização da necessidade de tornar o tratamento mais humanizado e do intuito de contemplar as perspectivas de assistência ao recém-nascido em tratamento com fototerapia. 
O relato de experiência se traduz em texto acadêmico que descreve precisamente uma dada experiência que possa contribuir de forma relevante para sua área de atuação profissional. Caracteriza-se por uma vivência consideradaimportante para a formação dos futuros profissionais da área da enfermagem, em seu meio acadêmico e contribui com a discussão, análise e a proposição de estratégias para a melhoria do cuidado em saúde, neste caso específico, com a melhora da qualidade de vida de RNs institucionalizados para tratamento com fototerapia (FLICK, 2004).

De acordo com Cortes, Padoin e Berbel (2018) o relato contribui como um método de ensino, que visa resolver ou minimizar problemas evidenciados em prática, possibilitando ao aluno uma reflexão crítica e minuciosa.

A atividade foi realizada como ação extensionista dentro da disciplina teóricoprática de Atenção Integral ao Recém-nascido, Criança e Adolescente do curso de Enfermagem da Universidade Franciscana - UFN, disciplina pertencente à matriz curricular do sexto semestre. Aconteceu no ambiente onde foram realizadas as atividades práticas da disciplina, ou seja, em uma maternidade de um hospitalpúblico, na cidade de Santa Maria- RS.

\section{RESULTADOS E DISCUSSÕES}

Dentre os manejos terapêuticos indicados para a icterícia, encontram-se o estímulo e encorajamento do aleitamento materno em livre demanda e a fototerapia no RN por meio do banho de luz, que promove a excreção da bilirrubina com a foto isomerização. O tratamento para icterícia é um procedimento demorado e que requer alguns cuidados acerca do posicionamento, nudez e oclusão ocular dos recémnascidos, esses cuidados, muitas vezes dificulta o vínculo mãe-bebê, pois delimitam as mamadas, o contato pele a pele e a interação pais-bebê. A fototerapia 
pode gerar isolamento social, diminuição dos estímulos neuro sensitivos, alteração dos ritmos biológicos e alteração da alimentação (FARIA et.al., 2021).

Em ambiente prático, observou-se que a indicação ao tratamento de fototerapia causava nas mães, em situação de acompanhante dos RNs, um certo temor, tanto por não terem conhecimento sobre o procedimento e sua efetividade, mas também por conforto do bebê e aparência visual geral. Baseado nessas condições, buscando sempre o bem estar do paciente e tornar a permenância na instituição e efetividade da prestação ao cuidado, surgiu a ideia de criar um dispositivo que além de eficaz, fosse confortável e visuavelmente agradável.

Com o intuito de melhorar o conforto e proteção aos recém-nascidos e para as mães/acompanhantes, tornar a prática mais leve com um aspecto visual menos traumático, visto que foi observado, durante as atividades, que ao ser diagnosticado que o RN necessitava de tratamento de fototerapia, eram improvisadas vendas de gaze com algodão e micropore, para a proteção ocular. O dispositivo adaptado, causava, aos olhos das mães, uma visão desconfortável, que atribuía a prática da fototerapia, uma técnica traumatizante, de certa forma.

Para o desenvolvimento do dispositivo, foram utilizados materiais de baixo custo e fácil acesso, na intenção de tornar o mesmo com custo-benefício alto e de forma que fosse do alcance de toda unidade de internação, sem causar gastos que possam vir a prejudicar o faturamento da instituição.

Para a produção, foram utilizadas tiras de tecido denominadas de feltro que se caracteriza por um tecido macio, na intenção de tornar o toque agradável à pele do $\mathrm{RN}$, linha de costura, tesoura e meia calça de seda para fazer a parte que envolve perímetro cefálico. Para que os olhos ficassem bem vendados, foi mantida a parte de proteção anterior aos olhos, duplo, foram costuradas as partes laterais e inferior, deixando a parte superior aberta para colocação de um papel escuro, ou de uma gaze dobrada, objetivando reduzir a permeabilidade da luz, envolto com gaze e algodão, este material irá ser introduzido dentro do protetor ocular de tecido, de forma que se ajuste melhor a face do $\mathrm{RN}$, aumentando não só a proteção como a sensação de conforto.

Alguns autores recomendam a produção do protetor ocular com material improvisado utilizando bandagens e fita-crepe, porém a maioria deles indica o uso de uma cobertura específica para fototerapia, produzida com material radiopaco por meio de camadas de veludo negro ou papel carbono negro envolto em gaze. 0 
EDUCAÇÃO, SAÚDE

ETECNOLOGIA

26 A 28 DE OUTUBRO DE 2021

\section{QUFN}

dispositivo abordado, foi projetado para ser utilizado com a junção do protetor radiopaco envolto com bandagens e crepe e o tecido do qual foi produzido, no intuito de conforto, maior proteção e melhoria da visão e condição ao que o RN se encontra (GONÇALVES et al., 2016). 
Após o planejamento e a produção, implementação do dispositivo, deu-se a partir de uma capacitação destinada aos profissionais atuantes na unidade, onde as acadêmicas responsáveis pela atividade, explicaram quais as fragilidades foram visualizadas para que surgisse a percepção da necessidade da criação desta tecnologia, os benefícios que ela tende a oferecer, assim como o material, a forma de que foi criada e de como a mesma deve ser implementada dentro da unidade.

Embora seja efetiva, a fototerapia não é isenta de efeitos indesejáveis, alterações oculares decorrentes da fototerapia podem ser ocasionadas tanto por uma exposição acidental à energia luminosa, devido ao uso e/ou posicionamento inadequado do protetor ocular, quanto pela não dispensação dos cuidados oculares recomendados durante a terapêutica. A exposição constante do RN com os raios da fototerapia pode levar ao ressecamento da córnea, assim como o estímulo luminoso constante na região ocular pode favorecer o descolamento da retina, em virtude de a vascularização desse componente ainda ser imatura (GONÇALVES et al., 2016).

Dentre os cuidados com o RN em fototerapia um dos principais cuidados está relacionado com os olhos, por meio da utilização de protetor radiopaco para prevenir a exposição à luz. A cobertura deve ter tamanho adequado e ser posicionada a fim de cobrir completamente os olhos. Tal cuidado evita e previne que venha ocorrer complicação da degeneração da retina pela exposição à luz. Cabe ao profissional de enfermagem o cuidado de orientar a genitora e aos familiares quanto aos cuidados inerentes ao RN sob fototerapia, frisando no que diz respeito ao monitoramento constante do posicionamento do protetor ocular. Faz-se necessária a adoção de medidas que visem à proteção do RN e para o sucesso da terapêutica (GONÇALVES et al., 2016).

\section{CONCLUSÃO}

Tendo em vista os aspectos apresentados, o protetor ocular ajuda e bloqueia a passagem dos raios de luz irradiados pelo equipamento de fototerapia, contribui na proteção e prevenção de agravos provenientes desse tratamento. Concluímos que a doaçaão do protetor para hospital, venha ao encontro de um tratamento mais confortável para a mãe-bebê, que diminua a ansiedade e que venha ser utilizado e 
orientado por toda a equipe de enfermagem como um modo humanizado, criativo e inovador que possibilita uma experiência mais benéfica e menos traumática.

Enfim, esperemos que esta ação criada, executada e implementada dentro do ambiente hospitalar contribua para todos os $\mathrm{RN}$ que passam pela maternidade e que possam, a curto, médio e a longo prazo alcançar os objetivos aos quais foi embasado a criação.

\section{REFERÊNCIAS}

BRASIL. Ministério da Saúde. Icterícia. In: Brasil. Ministério da Saúde. Atenção à saúde do recém-nascido: guia para os profissionais de saúde; v. 1.

Brasília: Ministério da Saúde, 2011. p. 59-77. Disponível em:

http://bvsms.saude.gov.br/bvs/publicacoes/atencao recem nascido \%20guia profis sionais \%20saude v2.pdf. Acesso em: 03/05/2021.

CORTES, L. F.; PADOIN, S. M. de M.; BERBEL, N. A. N.. Metodologia de Problematização e Pesquisa Convergente em Saúde: proposta de práxis em pesquisa. Rev. Bras. Enferm., Brasília, v. 71, n. 2, p. 440-445, Abr. 2018. Disponível em:http://www.scielo.br/scielo.php?script=sci arttext\&pid=S003471672018000200440\&lng=en\&nrm=iso. Acesso em 07/09/2021.

FARIA, J. F. de; et al.,Characteristics and effects of phototherapy in newborn: integrative review. Research, Society and Development, [S. I.], v. 10, n. 2, p. e19610212412, 2021. DOI: 10.33448/rsd-v10i2.12412. Disponível em:https://rsdjournal.org/index.php/rsd/article/view/12412 .

FLICK, U. Uma introdução à pesquisa qualitativa. 2. ed. Porto Alegre: Bookman, 2004.

GONÇALVES, P.A et al., Cuidados oculares ao recém-nascido sob fototerapia: conhecendo a prática de enfermagem. Rev enferm. UFPE on line., Recife, v.10, p. 2386-2394, jul. 2016. Disponível em:

https://periodicos.ufpe.br/revistas/revistaenfermagem/article/view/11294/12954\#. Acesso em: 13/09/2021.

SILVA, L. et al., Desenvolvimento de um protetor ocular para fototerapia em recémnascidos: uma tecnologia. Rev Latino-am Enfermagem, v. 16. 2008. Disponível em: https://www.scielo.br/pdf/rlae/v16n1/pt 07.pdf. Acesso em: 03/05/2021. 